\title{
The Dynamic Roles of Visfatin and Obestatin Serum Concentration in Pancreatic Beta Cells Dysfunction (HOMA- $\beta$ ) and Insulin Resistance (HOMA-IR) in Centrally Obese Men
}

\author{
Bayu Winata Putera ${ }^{1,2 *}$, Cynthia Retna Sartika ${ }^{1,4}$, Andi Wijaya ${ }^{1,3}$ \\ 'Post Graduate Program in Clinical Biochemistry, Hasanuddin University, Jl. Perintis Kemerdekaan Km. 10, Makassar, Indonesia \\ ${ }^{2}$ Prodia Clinical Laboratory, Jl. Let. Jend. S. Parman No 17/223 G, Medan, Indonesia \\ ${ }^{3}$ Prodia Clinical Laboratory, Jl. Cisangkuy No. 2, Bandung, Indonesia \\ ${ }^{4}$ Prodia Stem Cell Indonesia, Jl. Kramat 7 No. 11, Jakarta, Indonesia \\ ${ }^{\star}$ Correspondence: bayu.winata@prodia.co.id
}

\section{Abstract}

$\mathrm{B}$

ACKGROUND: Obesity is a majorhealth problem in the world today. Obesity is closely associated with insulin resistance and type 2 diabetes. Epidemiological studies have shown that obese persons are in a state of insulin resistance, however, most of them do not progress to type 2 diabetes. This occurs because the beta cell function is still good enough for maintaining normal glucose level. Obestatin and visfatin are cytokines that are known to have a role in beta cell function. The aim of this study was to assess the relationship between visfatin and obestatin and Homeostasis Model Assessment of beta cell function (HOMA- $\beta$ ) and Homeostasis Model Assessment of insulin resistance (HOMA-IR).

METHODS: This was a cross-sectional study involving 80 central obesity men with waist circumference $>90 \mathrm{~cm}$, age 30-65 years old. Visfatin and obestatin were measured by ELISA method. Beta pancreas cell dysfuction and insulin resistance were calculated by HOMA model.

RESULTS: Our study showed a correlation between visfatin and HOMA- $\beta(r=0.244$ and $p=0.029)$ and visfatin with HOMA-IR $(r=0.287$ and $\mathrm{p}=0.001)$ and no correlation was found between obestatin with HOMA- $\beta$ $(\mathrm{r}=0.010$ and $\mathrm{p}=0.990)$ and obestatin with HOMAIR $(r=0.080$ and 0.480$)$. We also found visfatin and obestatin concentrations were fluctuative depending on the measurements of the waist circumferences.

CONCLUSIONS: High visfatin and low obestatin concentration were independently associated with increased beta pancreas cell dysfunction and insulin resistance.

KEYWORDS: Obesity, Visfatin, Obestatin, Beta cell dysfunction (HOMA- $\beta$ ), Insulin resistance (HOMA-IR)

Indones Biomed J 2012; 4 (1): 43-49

\section{Introduction}

Obesity is a major health problem in the world today. Obesity is a risk factor for diabetes, heart disease and other metabolic disorders. It has become a serious public health problem increasingly affecting people in many countries (1). 
In the condition of obesity there is imbalance between energy intake and nutritional requirements. This energy imbalance causes excess of energy storage in the form of triglycerides in adipose cells that causes hypertrophy and hyperplasia of the adipose cells. Evidence suggests that adipocyte hyperplasia or adipogenesis occurs throughout life, both in response to normal cell turnover as well as to the need for additional fat mass stores that arises when caloric intake exceeds the nutritional requirements (2-4).

Adipose tissue metabolism is extremely dynamic. Adipose tissue possesses the ability to a very large extent to modulate its own metabolic activities like cytokine secretions. This condition correlates with obesity-related disorders (5). Currently, abdominal adipose cell size has been identified as a predictor for the development of diabetes mellitus (6).

Visfatin is a cytokine that is secreted by the adipose tissue (7) when the adipose cells enlarge (8). The role of visfatin in the development of obesity is in its feature as a proinflamatory cytokine (9). Increased levels of proinflamatory cytokines can lead to apoptosis of the pancreatic beta cells (10) and insulin resistance (11).

Obestatin is a product of ghrelin gene which reduces nutritional intake and hence the weight (20). Previous studies have shown that obestatin might play a role as antiapoptosis pancreas beta cells (13).

Presently it is still unclear about how the correlation between visfatin and obestatin can lead to beta pancreas cell dysfunction and insulin resistance. The influencing role of visfatin and obestatin to beta pancreas cells is very interesting to be studied, such as on how is the correlation of visfatin and obestatin with the incidence of beta pancreas cell dysfunction and insulin resistance.

\section{Methods}

This was an observational study with a cross sectional design. Eighty obese subjects aged $30-65$ years were included with the following criteria: systolic blood pressure $(\mathrm{BP})<140 \mathrm{mmHg}$ and diastolic $\mathrm{BP}<90$ $\mathrm{mmHg}$, serum hsCRP levels $<10 \mathrm{mg} / \mathrm{L}$, not using oral anti-diabetic such as sulfonilurea. All participants signed an informed consent registered to the Ethics Committee of Hasanuddin University Makassar (UH12030061), to allow records of their personal data such as height, weight, waist circumference, blood pressure, physical activity and drugs. Subjects were put in fasting for 10-12 hours. Obese was defined as waist circumference $>90 \mathrm{~cm}$, beta cell dysfunction was defined as HOMA- $\beta<107$ (14) and Insulin Resistance was defined as HOMA-IR $>2$.

\section{ASSAYS OF BIOCHEMICAL MARKERS}

Venous blood specimens were drawn and the serum was immediately separated by centrifugation and stored at $-20^{\circ} \mathrm{C}$ until measurement. Serum visfatin levels were measured by Enzyme Linked ImmunoAssay (ELISA) using AdipoGen. Serum glucose levels were measured by hexokinase using kit reagen Modular Roche Diagnostic $\mathrm{GmbH}$. Serum Insulin levels were measured by Chemiluminescent Immunometric Assay using kit from Siemens. The HOMA model was used to calculate IR and insulin secretion. The formula are as follows (15):

$$
\text { HOMA-IR }=\frac{F I \times G}{22,5} \quad \text { HOMA- } \beta=\frac{20 \times F I}{G-3,5}
$$

Where $\mathrm{FI}=$ fasting insulin $\mu \mathrm{IU} / \mathrm{mL}$ and $\mathrm{G}=$ fasting glucose $(\mathrm{mmol} / \mathrm{L})$.

\section{STATISTICAL ANALYSIS}

Statistical analysis was performed with SPSS for Windows ver. 15. Univariate analysis was performed to calculate mean, maximum sand minimum value as well as Standard Deviation (SD). Bivariate and partial correlation analysis were used to analyze the correlation of all factors. Results were considered significant if $\mathrm{p} \leq 0.05$. Scatter diagram analysis was used to analyze the role of dynamic of visfatin.

\section{Results}

The subjects' anthropometric measurements (height, weight, BMI, waist circumference) and biochemical measurements (fasting glucose, fasting insulin, hsCRP, visfatin, obestatin) were recorded. Then HOMA- $\beta$ and HOMA-IR were calculated with HOMA model. Table 1 shows the study subjects' characteristics. Characteristics normality test done by the Kolmogorov-Smirnov test showed the data had a normal distribution except for hsCRP, visfatin and obestatin.

Pearson or Spearmans correlation test was performed to assess correlation of waist circumferance, HOMA- $\beta$ and HOMA-IR with visfatin. Table 2 shows that the concentration of visfatin has correlation with waist circumference $(r=0.249)$, HOMA- $\beta(r=0.244)$ and HOMA-IR $(r=0.287)$. 


\section{Table 1. Subjects' characteristics}

\begin{tabular}{lccccc}
\hline Characteristic & Min & Max & Median & Mean \pm SD & $p$ \\
\hline Physical & & & & & \\
Age (years) & 31.0 & 61.0 & 42.50 & $43.90 \pm 8.79$ & $0.363 \#$ \\
BMl $\left(\mathrm{kg} / \mathrm{m}^{2}\right)$ & 23.2 & 42.7 & 28.06 & $29.12 \pm 3.54$ & $0.131 \#$ \\
WC $(\mathrm{cm})$ & 91.0 & 125.0 & 96.00 & $98.36 \pm 7.21$ & $0.083 \#$ \\
Biochemical & & & & & \\
FG $(\mathrm{mg} / \mathrm{dL})$ & 82.0 & 117.0 & 95.00 & $96.68 \pm 7.05$ & $0.160 \#$ \\
hsCRP $(\mathrm{mg} / \mathrm{dL})$ & 0.297 & 8.5 & 1.56 & $2.06 \pm 1.61$ & 0.035 \\
Insulin $(\mu \mathrm{IU} / \mathrm{mL})$ & 6.0 & 43.0 & 14.85 & $16.66 \pm 7.24$ & $0.095 \#$ \\
Parameter study & & & & & \\
Visfatib $(\mathrm{mg} / \mathrm{mL})$ & 0.06 & 8.0 & 0.75 & $1.15 \pm 1.27$ & 0.000 \\
Obestatin $(\mathrm{ng} / \mathrm{mL})$ & 2.0 & 7.0 & 3.02 & $3.12 \pm 0.81$ & 0.308 \\
HOMA-IR & 0.8 & 5.6 & 1.95 & $2.20 \pm 0.96$ & 0.029 \\
HOMA- $\beta$ & 70.2 & 242.2 & 132.35 & $139.14 \pm 40.65$ & $0.152 \#$ \\
& & & & & \\
\hline
\end{tabular}

Abbreviations: $\mathrm{SD}=$ Standard Deviation; $\mathrm{BMI}=$ Body Mass Index $; \mathrm{WC}=$ Waist Circumference; FG = Fasting Glucose; HOMA-IR = homeostasis model assessment - Insulin Resistance; HOMA- $\beta=$ homeostasis model assessment - beta.; \# = normal distribution.

Table 2. Pearson and Spearman's Correlation Analysis

\begin{tabular}{|c|c|c|}
\hline \multirow[b]{2}{*}{ Correlation } & \multicolumn{2}{|c|}{ Total $(n=80)$} \\
\hline & $\mathbf{R}$ & $\mathbf{P}$ \\
\hline \multicolumn{3}{|l|}{ WC vs } \\
\hline HOMA-IR & $0.379^{* *}$ & 0.001 \\
\hline HOMA- $\beta$ & $0.412^{* *}$ & 0.000 \\
\hline Visfatin & $0.249^{*}$ & 0.026 \\
\hline Obestatin & 0.113 & 0.318 \\
\hline \multicolumn{3}{|l|}{ HOMA-IR vs } \\
\hline HOMA- $\beta$ & $0.808^{\star \star}$ & 0.000 \\
\hline Visfatin & $0.287^{\star}$ & 0.010 \\
\hline Obestatin & 0.080 & 0.480 \\
\hline \multicolumn{3}{|l|}{ HOMA- $\beta$ vs } \\
\hline Visfatin & $0.244^{\star}$ & 0.029 \\
\hline Obestatin & 0.010 & 0.990 \\
\hline \multicolumn{3}{|l|}{ Visfatin vs } \\
\hline Obestatin & -0.012 & 0.915 \\
\hline
\end{tabular}

Abbreviations: WC $=$ Waist Circumference; HOMA-IR $=$ homeostasis model assessment - insulin resistance; HOMA- $\beta=$ homeostasis model assessment $-\beta$; ${ }^{* *}=$ Significant correlation with confidence level $99 \% ;{ }^{*}=$ Significant correlation with confidence level $95 \%$. 
Figure 1 shows that visfatin and obestatin serum concentrations fluctuated depending on waist circumference measurements. Obestatin increased in the condition of initial obesity at a waist circumference of 90-100 $\mathrm{cm}$ and then decreased at a waist circumference $>100 \mathrm{~cm}$. Visfatin serum concentrations decreased in the condition of initial obesity at a waist circumference $90-95$ $\mathrm{cm}$ and then increased at a waist circumference $>95 \mathrm{~cm}$.
Figure 2 shows that incidence of pancreatic beta cell dysfunction (HOMA- $\beta<107$ ) occurs in the condition with increased visfatin concentration while obestatin serum concentration decreased.

Figure 3 shows that incidence of insulin resistance (characterized by increased HOMA-IR) occurs in the condition of increasing visfatin concentration while obestatin serum concentration decreased.

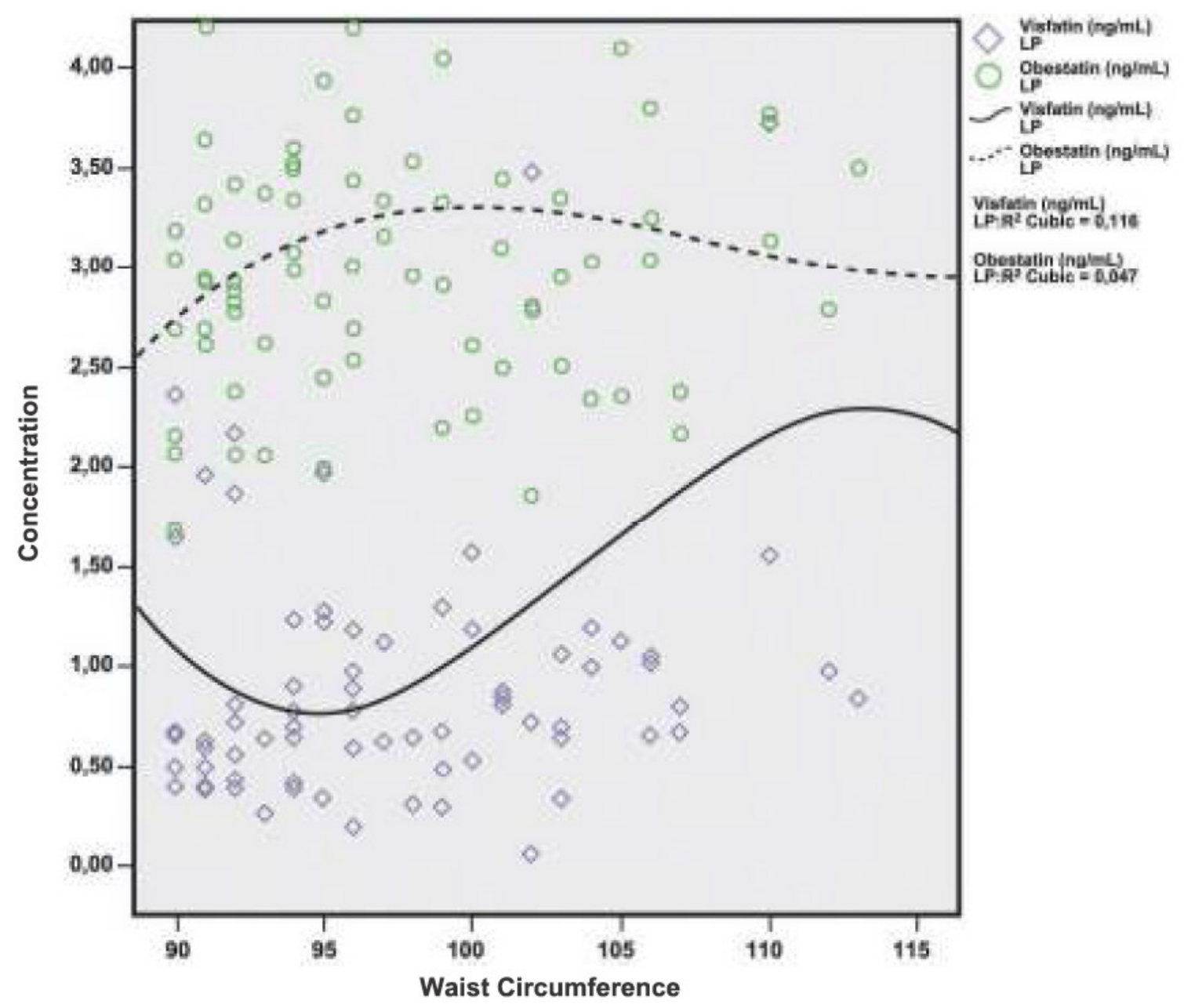

Figure 1. Scatter analysis of visfatin, obestatin and waist circumference. 


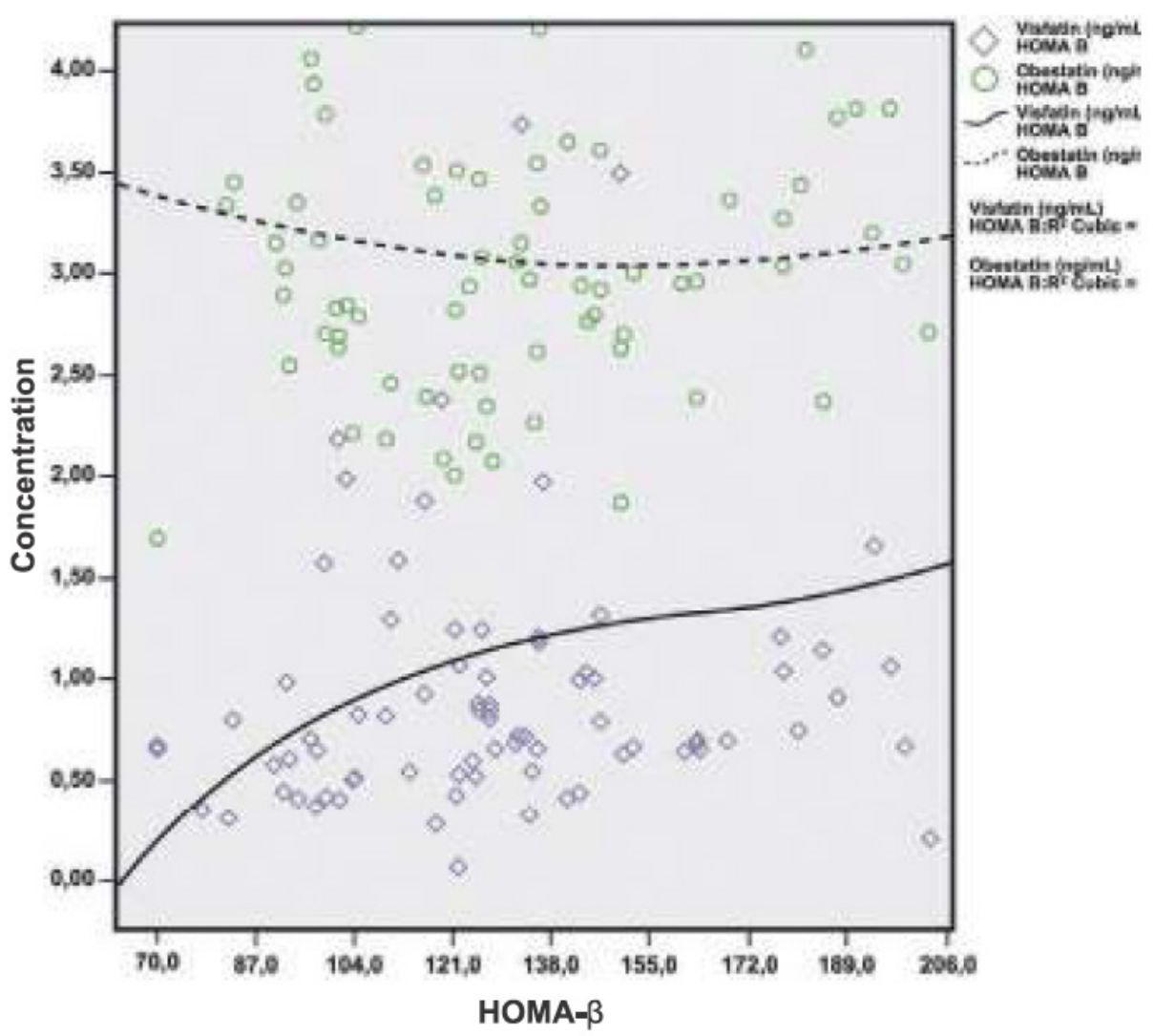

Figure 2. Scatter Analysis of Visfatin, Obestatin and HOMA- $\beta$.

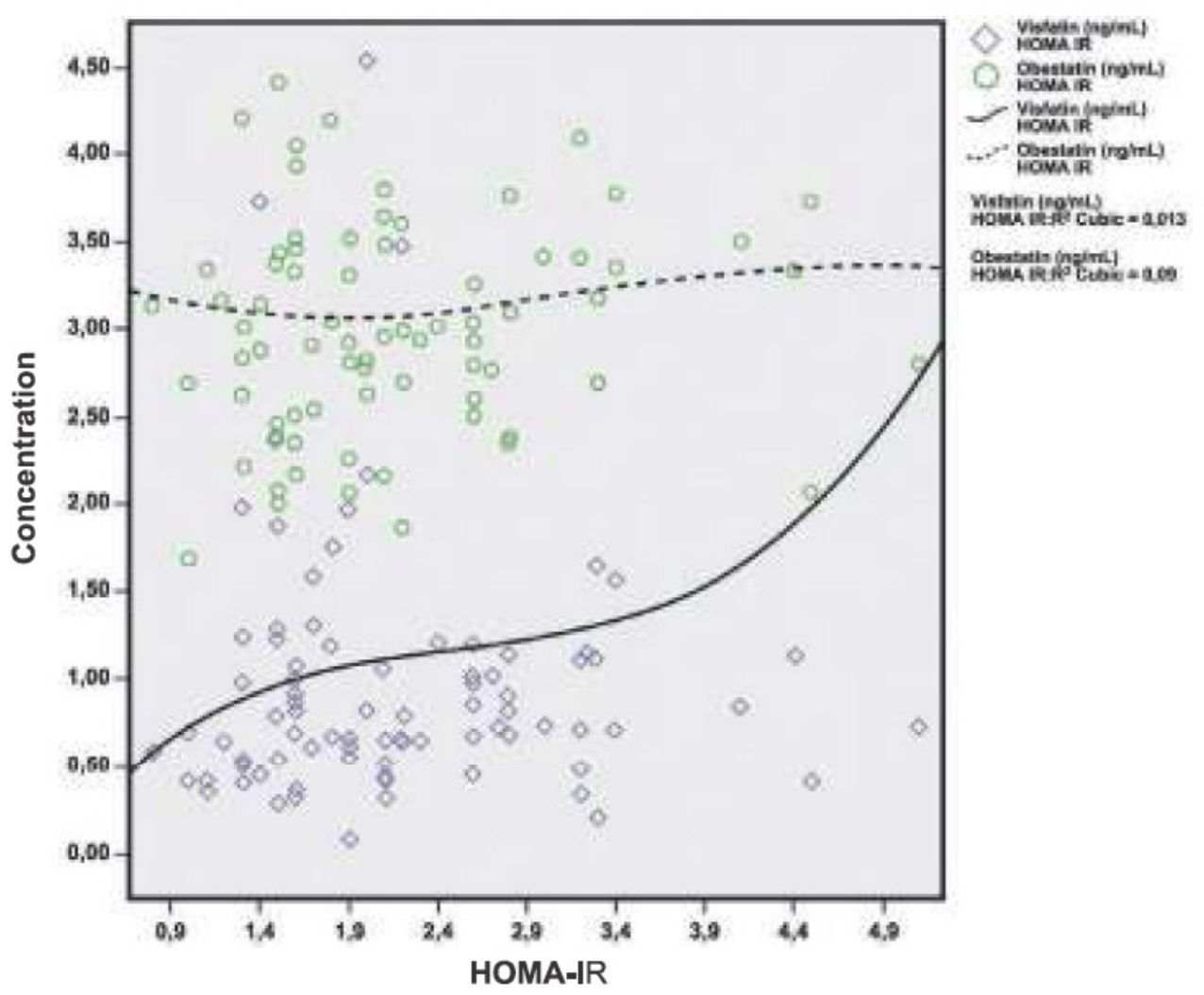

Figure 3. Scatter Analysis of Visfatin, Obestatin and HOMA-IR. 


\section{Discussion}

Obesity is a risk factor for diabetes mellitus. Diabetes mellitus is a metabolic disease characterized by increased glucose serum level. Glucose serum level is regulated by insulin hormone. Insulin is produced in the pancreas beta cells and its secretion occurs in two phases. In diabetic person, insulin secretion in phase $1 \mathrm{can}$ not lower serum glucose level, thus stimulating phase 2 to produce more insulin but is not able to increase insulin secretion as in normal individuals. This is due to the existence of dysfunction of pancreatic beta cells and insulin resistance in the peripheral tissues (15). HOMA-IR and HOMA- $\beta$ were used to assess the condition of insulin resistance and pancreatic beta cell dysfunction (16)

In this study, it was shown that incidence of beta pancreas cell dysfunction occurred when visfatin serum concentration began to increase while obestatin serum concentration decreased (Figure 2). Our study also showed that visfatin serum concentration had correlation $(\mathrm{r}=$ 0.249 ) with obesity (characterized by waist circumference $>90 \mathrm{~cm}$ ); this confirmed some previous studies that serum visfatin levels is increased in persons with obesity (17) and together with other proinflammatory cytokine such as Interleukin (IL)- $1 \beta$ can cause apoptosis of the pancreatic beta cells (11).

In obesity, energy imbalance occurs causing excess in the storage of energy as triglycerides in adipose cells, therefore, causing hypertrophy and hyperplasia of adipose cells (18). Our study has suggested that serum visfatin concentration decreases when individuals begin to have increased waist circumference $(90-94 \mathrm{~cm}$ ) (Figure 1) and that visfatin serum concentration increases when the waist circumference becomes $>95 \mathrm{~cm}$. Presumably with the waist circumference of 90-94 cm adipose cell enlargement (hypertrophy) starts to occur (19). The enlargement of adypocytes is associated with subtantial changes in metabolic function (5). Visfatin is a cytokines that is secreted by adipocyte cells (7). Visfatin might play a role as regulator Monocyte Chemoattractant Protein (MCP)-1 . Increasing MCP-1 would attract macrophages and T-cells to infiltrate into the adipose tissues (9), so it would secret more proinflammatory cytokines such as TNF- $\alpha$, IL-6 and IL-1 $\beta$ (10). Proinflammatory cytokines can lead to apoptosis of pancreatic beta cell dysfunction. Pancreatic beta cell apoptosis in the course of insulitis is probably caused by direct contact with activated macrophages and T-cells and/or exposure to soluble mediators secreted by these cells, including cytokines such as interleukin (IL)-1 $\beta$.
In vitro exposure of (IL)-1 $\beta$ to beta cells causes functional changes similar to those obeserved in pre-diabetic state (20).

Our study showed that pancreatic beta cells dysfunction (characterized by HOMA- $\beta<107$ ) occurs when visfatin serum concentration increases and obestatin serum concentration decreases. Obestatin prevents apoptosis of the pancreatic beta cells through survival promoting of pancreatic beta cells. Moreover, obestatin activates signaling pathways and induces expression of genes that regulate beta cell growth. Obestatin upregulates beta cell cAMP which is a main regulator of beta cell growth and survival (13).

Our study also confirmed previous studies that stated obestatin was secreted from the stomach with pulsatile (21). We investigated whether obestatin serum concentration had fluctuative levels depending on the waist circumference (Figure 1). Serum obestatin concentration increased when the individuals began to have increased waist circumference (90-94 cm) and then decreased when the waist circumference became $>100 \mathrm{~cm}$ (Figure 1). Presumably with the waist circumference of $(90-94 \mathrm{~cm})$ there occurs adipogenesis (hyperplasia) (19). Our results confirmed previous studies that found obestatin was secreted when adipogenesis occurred. Obestatin might play a role as a regulator of adipocyte metabolism and adipogenesis (hyperplasia) process. Pre-adipocyte and adipocyte 3T3-L1 cells were used to assess the obestatin effect on the cell metabolism and adipogenesis based on the regulation of the key enzymatic nodes, Akt and AMPK and their downstream targets. Obestatin activates Akt and its downstream target and simultaneously obestatin inactivated AMPK (22).

Our study showed that incidence of insulin resistance occurred when visfatin serum concentration increased and obestatin decreased (Figure 3). In obesity, there is a condition of meta-inflammation which secretes visfatin. Visfatin as a regulator of MCP-1 attracts macrophage to infiltrate adipose tissue. Macrophage secretes proinflammatory cytokine such as TNF- $\alpha$. TNF- $\alpha$ activates serine kinases such as JUN N-terminal kinase (JNK) and IK $\beta$ kinase (IKK) which phosphorylates serine residues of IRS-1 and disrupts insulin signaling. Both JNK and IKK are likely activated in insulin-resistant state and thus provide potential connection between inflammation and insulin resistance (10). In contrast, obestatin can activate Akt. The phosphatidylinositol 3-kinase (PI3K)-8 AKT pathway is largely responsible for insulin action in the glucose uptake. Decrease in obestatin serum concentration may cause to insulin resistance. 


\section{Conclusions}

From our study we can conclude that there is fluctuation of the increase of visfatin and obestatin serum concentration in obese subjects. Incidence of pancreatic beta cell dysfunction and insulin resistance occurs when visfatin serum concentration increases and obestatin serum concentration decreases.

\section{Acknowledgement:}

We thank the Prodia Education Research Institute for their invaluable support to this study.

\section{References:}

1. Antuna-Puente, B. Feve, S. Fellahi, J.P Bastard. Adipokines: The missing link between insulin resistance and obesity. Diabetes Metab.2008; 34: 2-11.

2. Avram MM, Avram AS, James WD. Subcutaneous fat in normal and diseases state 3 , adipogenesis: from stem cell to fat cell. J Am Acad Dermatol. 2007; 56: 472-92.

3. Sethi JK, Puig JV. Adipose tissue function and plasticity orchestrate nutritional adaption. J Lipid Res. 2007; 48: 1253-62.

4. Wallen KE, Hotamisligil GS. Inflammation, stress and diabetes. J Clin Invest. 2005; 115: 1111-8.

5. Engfeldt $P$, Arner $P$. Lipolysis in human adipocytes, effect of cell size, age and regional differences. Horm Metab Res Suppl. 1988;19:26-9.

6. Weyer C, Foley JE, Bogardus C, Tataranni PA, Pratley RES. Enlarged subcutaneous abdominal adipocyte size but not obesity itself, predict type II diabetes independent of insulin resistance. Diabetologia. 2000; 43: 1498-506.

7. Beltowski J. Apelin and Visfatin:Unique "beneficial" adipokines upregulated in obesity?. Med Sci Monit 2006; 12: RA112-9,

8. Berndt J., Kloting N., Kralisch S., Kovacs P., Fasshauer M., Schon M.R., Stumvoll et al. Plasma visfatin concentration and fat depot-specific mRNA expression in humans. Diabetes. 2005; 54: 2911-6.
9. Sommer Grit, Susan Kralisch, Nora Kloting, Manja Kamprad, Kathleen Schrock, Jurgen Kratzch, et al. Visfatin is A Positive Regulator of MCP-1 In Human Adipocytes In Vitro and In Mice In Vivo. Obesity. 2010; 18: 1486-92

10. Rocha VZ, Folco EJ. Inflamatory Concept of Obesity. Int J Inflam. 2011: 61-75.

11. Qatanani M, Lazar MA. Mechanisms of Obesity-Associated Insulin Resistance: Many Choices of Menu. Genes Dev. 2007; 21: 1443-55.

12. Hassouna R, Zizzari P, Tolle V. The Ghrelin/Obestatin Balance in Physiological and Pathological Control of Growth Hormone Secretion, Body Composition \& Food Intake. J Neuroendocrinol 2010; 22: 793-804.

13. Granata R, Settanni F, Gallo D, Trovato L, Biancone L, Cantaluppi $\mathrm{V}$, et al. Obestatin Promotes Survival of Pancreatic Beta Cells \& Human Islets and Induces Expression of Genes Involved in the Regulation of Beta-Cell Mass \& Function. Diabetes 2008; 57: 967-79.

14. Ciampelli M, Leoni F, Cucinelli F, Mancuso S, Panunzi S, De Gaetano A, et al. Assessment of insulin sensitivity from measurements in the fasting state and during an oral glucose tolerance test in polycystic ovary syndrome and menopausal patients. J Clin Endocrinol \& Metab 2005; 90 : 1398-406.

15. Matthews, Hosker J.P, Rudenski A.S, Naylor B.A, Treacher D.F, Turner R.C. Homeostasis model assessment: insulin resistance and beta cell function from fasting plasma glucose and insulin concentrations in man. Diabetologia 1985; 28: 412-9.

16. Basir, Herni, A., Aman, M., Adam, F.MS., Adam, J.MS. Insulin Resistance and Beta Cell Dysfunction in Obese Subject with Dysglycemia. Medicinus 2009; 22: 137-41

17. Kamińska A, Kopczyńska E, Bronisz A, Zmudzińska M, Bieliński M, Borkowska A, et al. An Evaluation of Visfatin Levels in Obese Subject. Endokrynol Pol. 2010 ; 61: 169-73

18. Wellen KE, Hotamisligil GS. Inflamation, Stress and Diabetes. J Clin Invest. 2005; 115: 1111-8.

19. Trayhurn P. Adipocyte Biology. Obes Rev. 2007; 8 (suppl.1): $41-4$.

20. Cnop M, Welsh N, Jonas JC, Jörns A, Lenzen S, Eizirik DL. Mechanisms of Pancreatic $\beta$-Cells Death in Type 1 and Type 2 Diabetes, Many Differences, Few Similarities. Diabetes. 2005; 54: S97-S107.

21. Riesco M, Barcelo A, Vila M, Belmonte M, Ruiz O, LopezEscribano $\mathrm{H}$ et al. Plasma levels of visfatin and obestatin in morbidly obese subject with and without type 2 diabetes mellitus. Obesity and Metabolism 2009; 5: 9-12

22. Lacquaniti A, Donato V, Chirico V, Buemi A, Buemi M. Obestatin: An Interesting but Controversial Gut Hormone. Ann Nutr Metab 2011; 59: 193-9 